\title{
Enkripsi Data Citra Untuk Model Warna Rgb Dan Treshold Menggunakan Algoritma Hill Cipher
}

\author{
Ommi Alfina \\ UniversitasPotensiUtama Jurusan Teknik dan Ilmu Komputer, Jl. K.L. YosSudarso Km. 6.5 No.3-A, Medan Indonesia
}

\section{KEYWORDS}

Hill Chiper, RGB, Enkripsi Citra

CORRESPONDENCE

Phone: +6282277076061

E-mail: ny.aroen@gmail.com

\section{PENDAHULUAN}

Kriptografi merupakan sebuah metode untuk menjaga kerahasiaan pesan dari pihak yang tidak berkepentingan. Pesan dirahasiakan dengan cara mengacak nilai-nilai yang terdapat didalamnya sehingga membuat pesan tersebut tidak memiliki arti lagi dan tidak dapat diambil informasi dari pesan tersebut.

Citra digital dapat diartikan sebagai sebuah pesan karena didalamnya terdapat sejumlah informasi yang dapat digunakan sebagai penunjang aktifitas manusia dalam berinteraksi antar sesama. Kerahasiaan pesan yang terdapat dalam file citra juga dapat dijaga dengan metode kriptografi. Kriptografi pada citra digital dilakukan dengan cara merubah informasi warna pada tiap pixel dari citra tersebut, baik itu format bmp, jpeg ataupun berbagai model-model warna yang ada saat ini. Dengan berubahnya warna-warna di setiap pixel citra digital, pesan yang terkandung dalam sebuah citra tidak dapat diketahui lagi.

Banyak metode kriptografi yang bisa digunakan untuk memanipulasi warna yang terdapat dalam citra, salah satunya dengan metode kriptografi klasik, karena cukup dengan menggunakan kriptografi klasik, maka gambar digital yang telah terenkripsi telah mampu menghilangkan informasi yang terkandung dalam sebuah file citra. Metode kriptografi klasik pun juga terdiri dari berbagai macam algoritma, sehingga penulis disini ingin menguji salah satu dari algoritma tersebut. Metode yang akan dibahas disini adalah metode Hill Cipher, yaitu sebuah teknik penyandian dengan menggunakan ide perkalian matrik yang ditemukan oleh Leister S. Hill pada tahun 1929. Hill Cipher disini akan bekerja untuk perkalian matrik baris dengan matrik kolom.

\section{METODOLOGI PENELITIAN}

\section{Analisa Rencana Penelitian}

Pada penelitian ini proses yang akan dilakukan dibagi dalam 2 proses yaitu enkripsi dan dekripsi, seperti dilihat pada gambar.1

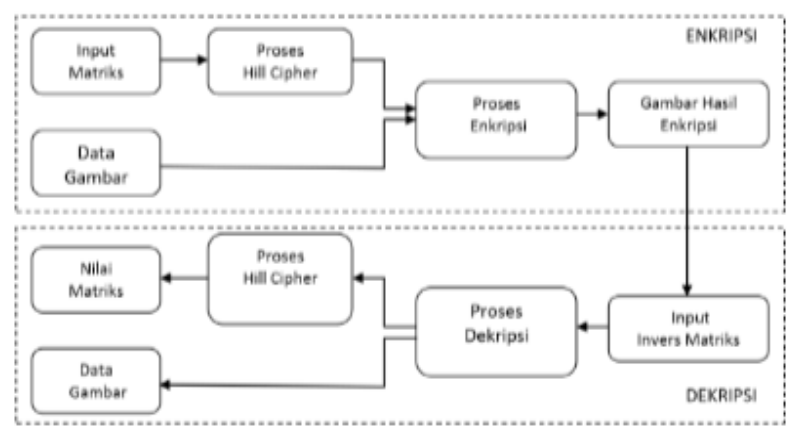

Gambar 1 Blok Diagram Program 
Tahap penelitian pada proses enkripsi yaitu mengambil inputan data berupa nilai matriks dan data gambar, selanjutnya akan dilakukan proses hill cipher untuk pengacakan data gambar, sehingga menghasilkan Hasil data gambar yang terenkripsi. Pada tahap dekripsi, hasil gambar enkripsi akan dilakukan proses dekripsi yaitu dengan cara mengambil data gambar yang terenkripsi dengan nilai input dari invers matrik awal. Selanjutnya dilakukan proses Hill Cipher balik sehingga dapat dikembalikan lagi data gambar yang telah diacak sehingga menghasilkan data gambar seperti semula.

\section{Metode Konversi Bilangan Desimal KeBiner}

Metode konversi yang digunakan untuk mengubah dari bilangan decimalmenjadi bilangan biner adalah dengan mengubah bilangan tersebut dari basis 10 menjadi basis 2 . Adapun caranya adalah dengan melakukan operasi modulus terhadap bilangan decimal tersebut dengan 2 sampai nilai tersebut habis di modulus, yang kemudian kita baca dari nilai bawah dari sisa hasil bagi. Berikut adalah untuk memperjelas tentang konversi dari bilangan decimal menjadi bilangan biner. Misal kita akan mencari bilangan biner dari 10, maka tahapan-tahapannya adalah

$10 \bmod 2=5$ sisa 0

$5 \bmod 2=2$ sisa 1

$2 \bmod 2=1$ sisa 0

Kemudian kita baca dari nilai yang paling bawah. Sehingga bilangan biner dari 10 adalah 1010 .

\section{Format Matrik Algoritma Hill Cipher}

Untuk penggunaana lgoritma Hill Cipher untuk enkripsi data ini, digunakan matrik dengan ordo $2 * 2$, Jadi dari nilai-nilai tersebut, akan diambil dan dikalikan dengan nilai yang didapat dari nilai warna RGB tiap-tiap pixel dari file gambar.

\section{Pengolahan Warna RGB}

Didalam Visual Basic 6 terdapat sebuah komponen atau kontrol yang digunakan untuk menampilkan sebuah citra gambar. Komponen tersebut adalah Image yang terdapat dalam kontrol standard. Citra gambar yang ditampilkan dalam Visual Basic. mempunyai format bitmap 24 bit, dimana tiap pixel yang mewakili representasi dari

sebuah citra terdiri dari 8 bit warna $R$ (Red), 8 bit warna $G$ (Green) dan 8 bit warna B

(Blue).

Dari teori diatas maka pengolahan warna RGB disini menggunakan metode

Little Endian yaitu sebuah metode pengambilan warna RGB dimana nilai 8 bit bawah

adalah nilai $\mathrm{R}$ dan nilai 8 bit atas adalah nilai $\mathrm{B}$. (Achmad:56,2005). Sehingga

implementasinya adalah dengan mengambil nilai tiap-tiap pixel dengan sintak point

yang dimiliki Visual Basic, kemudian melakukan operasi Little

Endian.Berikut adalah ilustrasi tentang pengolahan warna:

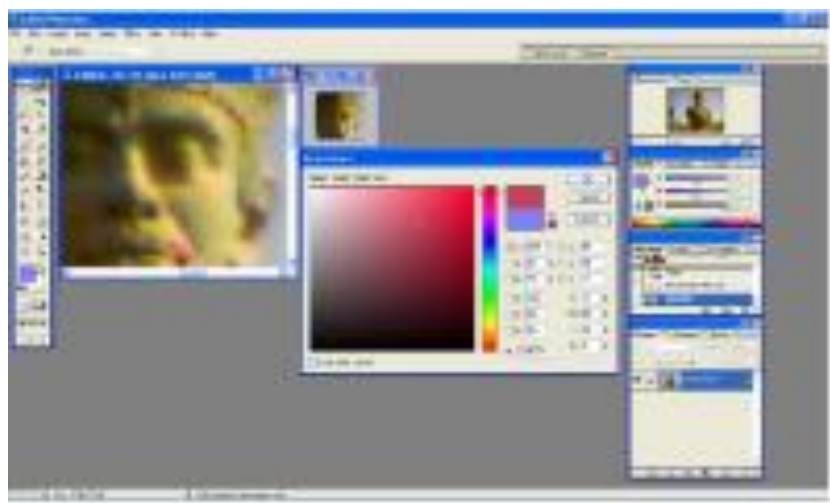

Gambar 2 Gambar Ilurstarsi Pengolahan Citra

\section{DFD (Data Flow Diagram) level 0}

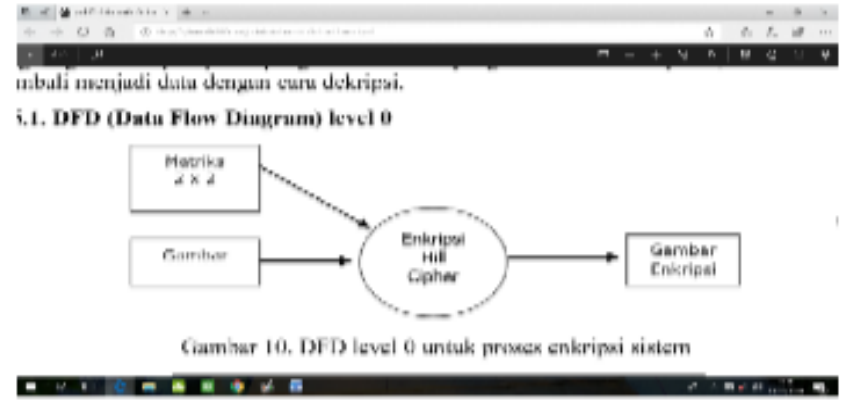

Gambar 3 DFD level 0 untuk proses enkripsi

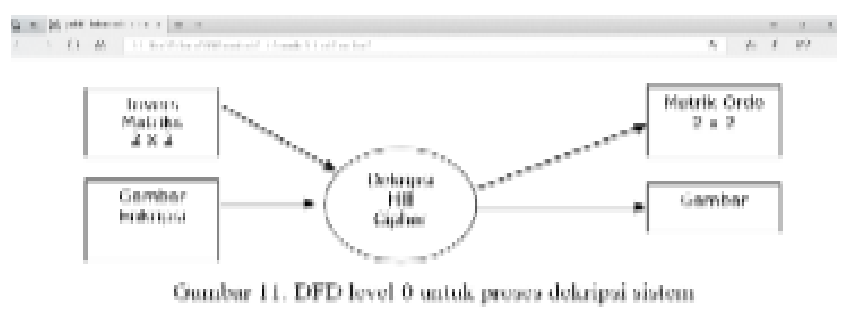

2. D+15 wow I

Gambar 4 DFD level 0 untuk proses dekripsi

\section{Menampilkan Metode Pengujian}

Untuk melakukan uji coba pada aplikasi program yang telah dibuat agar diketahui sejauh mana algoritma Hill Cipher dapat melakukan enkripsi dan dekripsi pada data berbentuk gambar(citra) maka dirancang sebuah tahapan-tahapan dalam pengujiannya. Pengujian dilakukan dengan format seperti pada table berikut: 
Tabel 1 Metode Pengujian

\begin{tabular}{c|c|c|l|}
$\begin{array}{c}\text { Pengujian } \\
\text { ke }\end{array}$ & MatriksEnkripsi & MatriksDekripsi & \multicolumn{1}{|c|}{ Citra } \\
\hline 1. & $\begin{array}{c}\mathrm{a}=11, \mathrm{~b}=12, \\
\mathrm{c}=10, \mathrm{~d}=11\end{array}$ & sesuai & Format True color berekstensi bmp \\
\hline 2. & $\begin{array}{c}\mathrm{a}=3, \mathrm{~b}=4, \\
\mathrm{c}=2, \mathrm{~d}=3\end{array}$ & sesuai & Format True color berekstensi br $\mathrm{p}$ \\
\hline 3. & $\begin{array}{c}\mathrm{a}=11, \mathrm{~b}=12, \\
\mathrm{c}=10, \mathrm{~d}=11\end{array}$ & sesuai & $\begin{array}{l}\text { Format Citra biner (threshold) } \\
\text { dengan level =100 }\end{array}$ \\
\hline 4. & $\begin{array}{c}\mathrm{a}=11, \mathrm{~b}=12, \\
\mathrm{c}=10, \mathrm{~d}=11\end{array}$ & sesuai & Format Citra keabuan (Grayscale) \\
\hline 5. & $\begin{array}{c}\mathrm{a}=11, \mathrm{~b}=12, \\
\mathrm{c}=10, \mathrm{~d}=11\end{array}$ & Tidaksesuai & Format True color berekstensi br $\mathrm{p}$ \\
\hline 6. & $\begin{array}{c}\mathrm{a}=5, \mathrm{~b}=2, \\
\mathrm{c}=8, \mathrm{~d}=4\end{array}$ & sesuai & Format True color berekstensi bmp \\
\hline
\end{tabular}

\section{HASIL DAN PENGUJIAN}

Untuk langkah pengujian program pada penelitian ini, maka penulis mencoba dengan menggunakan nilai input matriks, dan citra gambar yang berbeda-beda. Matriks yang digunakan adalah yang mempunyai determinan sama dengan 1 dan yang tidaK sama dengan 1. Untuk file citra yang digunakan adalah warna dalam beberapa mode grafis seperti RGB, Grayscale (abu-abu), Treshold (Hitam Putih) agar pengujian semakin beragam dan dapat menjelaskan program secara detai. Pengujian enkripsi menggunakan nilai matriks adalah, sedangkan file citra gambar adalah maudy.bmp seperti pada gambar.

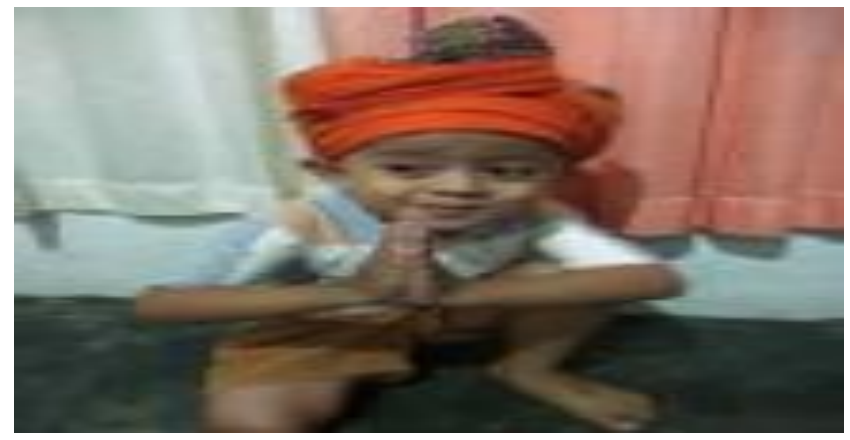

Gambar 7 Shanan.bmp

Dari nilai input matriks yang digunakan telah memenuhi nilai determinan matriks yaitu $(11 \times 11)-(12 \times 10)=1$, kemudian untuk file citra yaitu berekstensi bmp. Hasil pemrosesan adalah sebagai berikut:
Sedangkan untuk proses dekripsi dengan menggunakan nilai matriks yang sama dengan matriks pada waktu proses enkripsi berjalan sesuai dengan yang diharapkan yaitu file citra terenkripsi akan kembali ke bentuk gambar semula seperti pada gambar berikut:

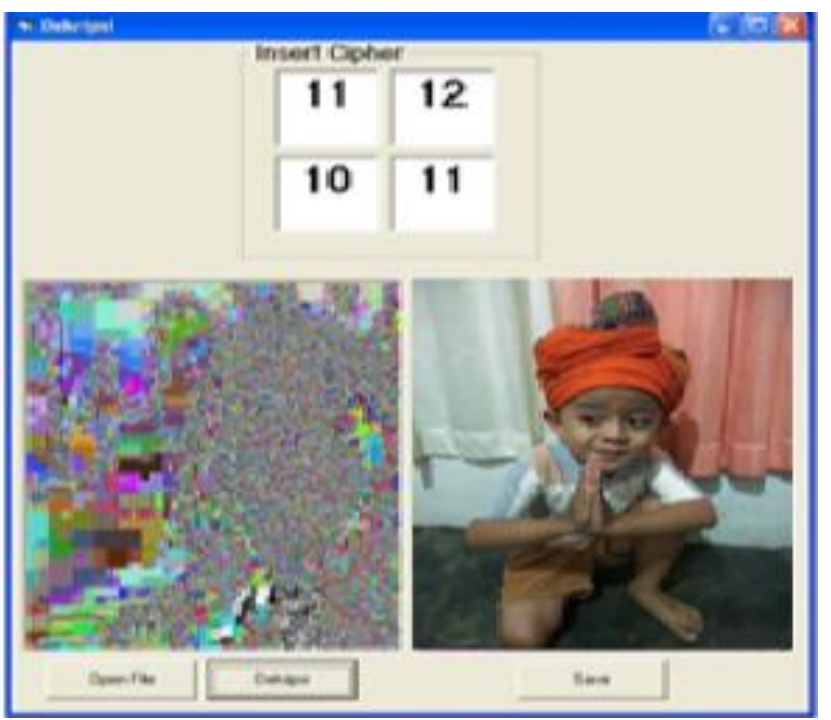

Gambar 9 Hasil Deskripsi Pengujian

\section{KESIMPULAN DAN SARAN}

Berdasarkan implementasi, analisa dan pembahasan yang telah dilakukan maka dapat diambil beberapa kesimpulan yaitu:

1. Objek Enkripsi dan dekripsi data dapat diterapkan pada data berupa citra atau gambar dengan cara mengambil bitbit nilai RGB dari tiap-tiap pixel yang berupa bilangan numeric, dimana nilainya berkisar antara $0-255$. Nilainilai pixel tersebutlah yang kemudian dioperasikan dengan perkalian matriks dari algoritma Hill Cipher.

2. Data berupa citra atau gambar yang dapat di enkripsi menggunakan algoritma Hill Cipher adalah citra yang true color dan grayscale, sedangkan untuk citra threshold (black and white) tidak dapat di enkripsi dikarenakan keragaman warna yang hanya sedikit, yaitu nilai yang hanya 0 dan 255. Untuk input data matrik algoritma Hill Cipher yaitu semakin besar nilai matrik yang dimasukkan, maka proses enkripsi akan semakin baik dan tidak mudah dikenali bentuk asalnya.

\section{DAFTAR PUSTAKA}

[1] Anton, Howard. Aljabar Linear Elementer, Penerbit Erlangga, 1998.

[2] Ariyus, Doni. Computer Security, Andi Yogyakarta, 2006.

[3] Jogiyanto, H.M. Pengenalan Komputer, Andi offset, Yogyakarta, 1990.

[4] Kurnia, Adi. Pemrograman Microsoft Visual Basic 6.Jakarta : PT. Elex Media Komputindo Kelompok Gramedia, 1999.

Gambar 8 Hasil Enkripsi Pengujian 
[5] Soehono, Stefanus. http://www.cert.or .id/ budi/courses/security/Stefanus_Soehono_report.doc, 2006.

[6] Stalling,William. Cryptography and Network Security Principles and Practices,Pearson Education, 2003.

[7] Wijaya,Rosyidah Jayanti..http://supriyanto.fisika.ui.edu/ matkom1.pdf, 2007. 